\title{
ANALISIS FAKTOR YANG MEMPENGARUHI "PREHOSPITAL DELAY TIME" PADA PASIEN NON-ST ELEVATION MYOCARDIAL INFARCTION (NSTEMI)
}

\section{FACTORS ASSOCIATED WITH PROLONGED PREHOSPITAL DELAY IN PATIENTS WITH NON-ST ELEVATION MYOCARDIAL INFARCTION (NSTEMI)}

\author{
Linda Widyarani ${ }^{1}$ \\ ${ }^{* 1}$ Akademi Keperawatan Notokusumo Yogyakarta, Jl. Bener No. 26 Tegalrejo Yogyakarta, \\ Email: lindawidyarani@gmail.com, Indonesia.
}

\begin{abstract}
Background: AMI is the leading cause of morbidity and disability among Indonesian population. In referrals centre hospital, in-hospital mortality of NSTEMI is equal or even exceeds STEMI, increased from $17 \%$ to $21 \%$ during 12 months. Prehospital delay is an important cause of increasing early and also late mortality in NSTEMI.

Objective: We investigated factors associated with prolonged prehospital delay in patients with NSTEMI.

Method: In this cross-sectional study design, data were analyzed by chi-square and one-way ANOVA using SPSS 20 and data were collected from 50 patients with NSTEMI using patient's medical notes and semistructured interviews. Patients were pain-free and hemodynamically stable at the time of interview. Data were collected on the time from the onset of chest pain to hospital admission.

Results: Mean of prehospital delay times were $7,89 \pm 1,44$ hours. The predictor were singularly significantly associated with prolonged prehospital delay were self medication and health care seeking pattern. Traditional healers had longest prehospital delay time $(24,30 \pm 2,65$ hours). Most of the people in Java from various social strata still believe in traditional healers (dukun) to treat their disease.

Conclusion: Health care providers can educate the public on NSTEMI to enable them recognize the signs and symptoms of NSTEMI correctly and realize the benefits of early treatment.
\end{abstract}

Keyword: Prehospital delay time and NSTEMI

\section{PENDAHULUAN}

Angka kejadian dan angka mortalitas NSTEMI telah mengalami pergeseran trend yaitu sama bahkan lebih tinggi dibandingkan STEMI. Di Malaysia, insidensi NSTEMI dalam periode 1 tahun (2007-2008) mencapai dua kali lipat yaitu 881 jiwa dibandingkan STEMI yang hanya 407 jiwa. $^{1}$ Peningkatan angka kejadian NSTEMI ini selaras dengan peningkatan angka mortalitas NSTEMI. ${ }^{2}$ Di Thailand, dilaporkan angka mortalitas NSTEMI juga lebih tinggi yaitu $13 \%$, dibandingkan STEMI yang hanya 9,6\%. ${ }^{3}$ Di Indonesia, Infark Miokardial Akut (IMA) merupakan salah satu 10 besar penyebab mortalitas selama rawat inap di rumah sakit. Angka mortalitas akibat IMA, baik NSTEMI dan STEMI mencapai 9,4\% pada tahun 2009 dan meningkat mencapai 14\%. ${ }^{4}$ Peningkatan angka mortalitas NSTEMI ini berhubungan dengan komplikasi klinis yang terjadi yaitu hipoperfusi sistemik akibat penurunan tekanan darah sistolik, syok kardiogenik, peningkatan kadar gula darah, atrial fibrilasi, gangguan konduksi jantung, disfungsi ginjal, riwayat stroke, gagal jantung dan DM. Komplikasi klinis tersebut lebih sering terjadi pada NSTEMI dibandingkan STEMI dan komplikasi inilah yang 
menyebabkan pasien NSTEMI berisiko lebih tinggi mengalami mortalitas. ${ }^{3}$

Di salah satu Rumah Sakit Pusat Rujukan di Provinsi Jawa Timur, pada tahun 2012, fakta yang sama juga terjadi, bahwa angka mortalitas mencapai 23 jiwa dari total pasien NSTEMI yaitu 138 jiwa dan pada tahun 2013, angka mortalitas mencapai 35 jiwa dari total pasien NSTEMI yaitu 166 jiwa. Dengan demikian angka mortalitas NSTEMI sudah mencapai angka $17 \%$ pada tahun 2012 dan semakin meningkat mencapai angka $21 \%$ pada tahun 2013, sedangkan angka mortalitas STEMI mengalami penurunan, yaitu 25\% pada tahun 2012 dan menurun menjadi 20\% pada tahun 2013. Dari hasil studi pendahuluan didapatkan bahwa kebanyakan pasien NSTEMI merupakan pasien yang membutuhkan perawatan intensif di ICCU dan berdasarkan data rekam medik, mortalitas NSTEMI paling sering terjadi pada 48 jam pertama perawatan. Angka mortalitas yang semakin meningkat ini dipengaruhi oleh interval kedatangan pasien di IGD, fakta yang terjadi $78 \%$ pasien NSTEMI datang terlambat di IGD. ${ }^{6}$

Interval kedatangan merupakan prediktor mortalitas pada pasien NSTEMI. Interval kedatangan adalah interval waktu yang dibutuhkan pasien sejak munculnya nyeri dada terberat pertama hingga datang di IGD. ${ }^{6}$ Definisi terlambat adalah apabila interval waktu yang dibutuhkan pasien sejak munculnya nyeri dada terberat pertama hingga datang di IGD adalah lebih dari 2 jam. ${ }^{7,8}$ Penyebab pasien NSTEMI datang terlambat di IGD adalah upaya selfmedication yang dilakukan oleh pasien $(34,5 \%)$ dan pola pencarian pengobatan (60\%). ${ }^{9,10}$ Pasien yang datang terlambat menganggap upaya self-medication mampu mengontrol keluhannya dan tidak akan berkembang menjadi infark atau kematian pada otot-otot jantung. ${ }^{11}$ Pasien beranggapan serangan nyeri dada yang dirasakan masih merupakan keluhan yang wajar, tidak serius dan akan hilang dengan sendirinya. ${ }^{11}$ Pasien yang datang terlambat ( $>2$ jam setelah onset muncul) mempunyai risiko mortalitas 3 kali lebih tinggi dibandingkan dengan pasien yang datang lebih awal ( $\leq 2$ jam setelah onset muncul) dengan nilai odd ratio (OR) 3,2. ${ }^{8}$

Self-medication diartikan sebagai segala tindakan atau upaya pasien sebagai respon terhadap keluhan nyeri dada yang dirasakan guna menjaga dan memelihara stabilitas fungsi fisiologisnya tanpa petunjuk dari dokter. ${ }^{12} 34,3 \%$ pasien terlambat datang di IGD disebabkan karena upaya selfmedication yang dilakukan pasien post serangan angina. ${ }^{13} \quad$ Self-medication merupakan penyebab pasien terlambat datang di IGD (OR 1,90). ${ }^{8}$ Kondisi ini terjadi karena kesalahan persepsi pasien terhadap keluhannya, pasien beranggapan bahwa upaya self-medication yang dilakukan mampu mengontrol keluhannya, tanpa berkembang menjadi kondisi miokard infark. Selain itu juga karena kondisi psikologis pasien yang masih dalam tahap denial untuk 
menerima bahwa mereka menderita miokard infark.

Pola pencarian pengobatan juga berperan sebagai penyebab pasien terlambat datang di IGD, 60\% pasien terlambat datang di IGD disebabkan karena pola pencarian pengobatan yang dilakukan. Kemampuan pasien untuk menginterpretasikan keluhan yang dirasakan berpengaruh terhadap perilaku pasien dalam menentukan pola pencarian pengobatan. ${ }^{14}$ Pasien yang mencari pertolongan pertama ke dokter keluarga mempunyai interval kedatangan lebih lama dibandingkan pasien yang mencari pertolongan pertama langsung ke rumah sakit setelah serangan nyeri dada. ${ }^{5}$ Pasien yang menginterpretasikan keluhannya bukan sebagai nyeri dada kardiak akan cenderung berperilaku mencari pertolongan bukan ke rumah sakit namun ke layanan P rimary Health Care (PHC) terlebih dahulu seperti puskesmas, praktek dokter keluarga, praktek perawat, dukun/kyai, klinik atau rumah sakit daerah.

Pasien yang mempunyai pola pencarian pengobatan ke layanan PHC berisiko 3,39 kali lebih besar mengalami keterlambatan untuk sampai di IGD. Pasien yang melakukan kontak pertama dengan ketika terjadi serangan nyeri dada dengan menghubungi layanan IGD RSSA rata-rata onsetnya adalah 3,9 $\pm 2,23$ jam sedangkan pasien yang menghubungi layanan $\mathrm{PHC}$ sebelum menuju ke IGD RSSA mempunyai rata-rata onset $5,32 \pm 2,68$ jam. Kondisi ini kemungkinan disebabkan karena layanan PHC yang dituju oleh pasien tidak memiliki fasilitas penunjang untuk menangani pasien dengan serangan nyeri dada kardiak. Selain itu, sarana prasarana yang dipergunakan untuk merujuk pasien ke IGD RSSA, seperti keterbatasan ambulans yang dimiliki oleh layanan tersebut, kesiapan dalam menjalankan sistem penggunaan ambulans, baik dari sopir maupun tenaga kesehatan yang mendampingi pasien ketika di ambulans atau keterbatasan pengetahuan tenaga kesehatan baik perawat dan dokter untuk segera merujuk pasien sehingga memperpanjang interval kedatangan pasien. ${ }^{15}$

Pasien beranggapan bahwa dirinya masih terlalu muda untuk mengalami serangan infark miokard, karena baginya serangan tersebut hanya menyerang usia lanjut. Pasien juga merasa bahwa dirinya sudah bergaya hidup sehat dalam kehidupan sehari-hari sehingga perasaan denial masih melekat pada diri pasien. Pasien juga merasa takut mati padahal dia masih mempunyai banyak tanggung jawab dalam kehidupannya. Nyeri dada yang dirasakan dianggap sebagai respon terhadap stress, kurang tidur dan kelelahan akibat bekerja terlalu keras sehingga pasien beranggapan bahwa dengan istirahat sejenak, tidur, merubah posisi dan meminum obat akan berhasil menghilangkan keluhannya. Dalam pengambilan keputusan untuk mencari pertolongan medis segera ke rumah sakit, 
juga sangat dipengaruhi oleh dukungan psikososial dari keluarga atau teman dekat. Pasien membutuhkan waktu untuk meyakinkan dirinya bahwa keluhannya merupakan tanda dari serangan infark miokard, yang kemudian akan membuat pasien segera mengambil keputusan dan juga segera mencari pertolongan medis ke rumah sakit. ${ }^{16}$ Dengan latar belakang tersebut, perlu dilakukan analisis tentang faktor-faktor yang mempengaruhi "Prehospital Delay Time" pada pasien NSTEMI di Rumah Sakit Pusat Rujukan di Provinsi Jawa Timur.

\section{BAHAN DAN CARA PE NE LITIAN}

Penelitian ini merupakan penelitian deskriptif analitik yaitu penelitian yang menjelaskan terdapat hubungan antar variabel melalui pengujian hipotesis. ${ }^{17}$ Peneliti melakukan wawancara secara langsung kepada responden terhadap variabel yang diteliti, namun dalam hal ini peneliti tidak melakukan intervensi atau perlakuan apapun. ${ }^{18}$ Desain penelitian dalam penelitian ini adalah prospektif cohort. Penelitian ini dilakukan pada bulan April sampai Juni 2016. Populasi dalam penelitian ini adalah semua pasien NSTEMI di IGD Rumah Sakit Pusat Rujukan di Provinsi Jawa Timur. Berdasarkan rumus yang diadopsi, jumlah sampel dalam penelitian ini adalah sebanyak 50 orang. ${ }^{19}$

Metode pengambilan sampel yang digunakan dalam penelitian ini menggunakan teknik non-probability sampling dengan pendekatan consecutive sampling yaitu semua subjek yang datang secara berurutan dan memenuhi kriteria inklusi dimasukkan dalam penelitian sampai jumlah subjek yang diperlukan terpenuhi. Peneliti menggunakan teknik consecutive sampling karena merupakan jenis teknik non-probability sampling yang paling baik dan seringkali merupakan cara termudah. ${ }^{17}$ Pemilihan sampel dengan consecutive (berurutan) adalah pemilihan sampel dengan menetapkan subjek yang memenuhi kriteria penelitian dimasukkan dalam penelitian sampai kurun waktu tertentu, sehingga jumlah responden yang diperlukan terpenuhi. ${ }^{26}$ Pengambilan data dilakukan melalui metode wawancara semi terstruktur dengan jenis pertanyaan terbuka. Pertanyaan terbuka tersebut dituangkan di lembar pedoman wawancara penelitian, dengan jumlah 6 item pertanyaan. Wawancara digali dari keluarga dengan syarat keluarga tersebut merupakan keluarga inti atau keluarga yang mengetahui secara persis kondisi pasien sejak awal serangan angina. Di lembar pedoman wawancara penelitian untuk item pertanyaan 1, 2, 3, 4, dan 5 digali dari keluarga, namun untuk item pertanyaan 1 dilakukan validasi langsung kepada pasien karena item pertanyaan ini bersifat subjektif dimana menanyakan waktu (jam) pasien mulai merasakan nyeri dada terberat sebagai tanda munculnya onset serangan. Validasi ini dilakukan saat pasien sudah berada di 
bangsal perawatan atau kondisi pasien sudah stabil dengan kriteria tidak ada keluhan nyeri dada $1 \times 24$ jam, tidak ada edema paru, tidak ada aritmia, hemodinamik stabil (tekanan darah sistolik dalam rentang $90 \mathrm{mmHg}$ sampai kurang dari $140 \mathrm{mmHg}$, tekanan darah diastolik dalam rentang 60 $\mathrm{mmHg}$ sampai kurang dari $90 \mathrm{mmHg}$, kecepatan nadi perifer 60-100x per menit, akral hangat, $R R$ 12-20x/menit dan suhu tubuh normal $36,5-37,5^{\circ} \mathrm{C}$ ), urine output normal $(0,5-1 \mathrm{ml} / \mathrm{kgBB} / \mathrm{jam})$ dan dinyatakan oleh dokter bahwa kondisi pasien sudah stabil.

Adapun kriteria inklusi yaitu pasien yang masuk di IGD dengan diagnosa dokter jaga IGD atau dokter spesialis kardiologi menderita NSTEMI, kondisi pasien sudah stabil, dengan kriteria yaitu tidak ada keluhan nyeri dada dalam $1 \times 24$ jam, tidak ada edema paru, tidak ada aritmia, hemodinamik stabil (tekanan darah sistolik dalam rentang 90 $\mathrm{mmHg}$ sampai kurang dari $140 \mathrm{mmHg}$, tekanan darah diastolik dalam rentang 60 $\mathrm{mmHg}$ sampai kurang dari $90 \mathrm{mmHg}$, kecepatan nadi perifer 60-100x per menit, akral hangat, $R R$ 12-20x/menit dan suhu tubuh normal $\left.36,5-37,5^{\circ} \mathrm{C}\right)$, urine output normal $(0,5-1 \mathrm{ml} / \mathrm{kgBB} / \mathrm{jam})$ dan dinyatakan oleh dokter bahwa kondisi pasien sudah stabil, bersedia menjadi responden. Instrumen yang digunakan pada penelitian ini adalah lembar pedoman wawancara, dalam bentuk pertanyaan terbuka, dengan 5 (lima) item pertanyaan, mencakup: 1) Jam berapa pasien merasakan nyeri dada terberat; 2) Apakah yang pasien lakukan setelah nyeri terberat dirasakan? Jam berapa? Alasan? Berapa lama? berhasil/tidak?; 3) Apabila tidak berhasil, apakah yang pasien lakukan? Apakah pasien langsung dibawa ke rumah sakit? Apakah alasannya?; 4) Siapa yang mengambil keputusan untuk segera membawa pasien ke rumah sakit? Apakah pasien sendiri atau keluarga?; 5) Jam berapa keputusan tersebut diambil?. Teknik pengolahan data dan analisis data menggunakan uji chi-square dan one-way ANOVA SPSS 20.

\section{HASIL DAN PEMBAHASAN}

Pada penelitian ini, jumlah responden laki-laki adalah 17 orang dengan prosentase $34 \%$ sedangkan jumlah responden perempuan adalah 33 orang dengan prosentase $66 \%$, sesuai dengan tabel 1 .

\begin{tabular}{|c|c|c|}
\hline $\begin{array}{c}\text { Karakteristik } \\
\text { Responden }\end{array}$ & $\begin{array}{c}\text { Frekuensi } \\
\text { (n) }\end{array}$ & $\begin{array}{c}\text { Prosentase } \\
(\%)\end{array}$ \\
\hline \multicolumn{3}{|l|}{ Jenis kelamin } \\
\hline Laki-laki & 17 & 34 \\
\hline Perempuan & 33 & 66 \\
\hline \multirow[t]{2}{*}{$\begin{array}{c}\text { Karakteristik } \\
\text { Responden }\end{array}$} & $\begin{array}{c}\text { Mean } \\
\text { (tahun) }\end{array}$ & SD \\
\hline & 50 & 100 \\
\hline \multicolumn{3}{|l|}{ Usia } \\
\hline Laki-laki & 65,71 & 7,498 \\
\hline Perempuan & 67,39 & 8,536 \\
\hline
\end{tabular}

Sumber : Data Primer, 2016

Rata-rata usia responden pada penelitian ini adalah 66,82 $\pm 8,16$ tahun. Tabel 3 
menunjukkan rata-rata interval kedatangan pasien di IGD.

Tabel 2. Rata-rata Interval Kedatangan Pasien di IGD (dalam jam) $(n=50)$

\begin{tabular}{cll}
\hline Variabel & Mean & SD \\
\hline Interval Kedatangan & 7.89 & 6.44 \\
\hline
\end{tabular}

Sumber : Data Primer, 2016

Interval kedatangan diartikan sebagai interval waktu sejak munculnya nyeri dada terberat hingga pasien datang di IGD.Tabel 2 menunjukkan bahwa rata-rata interval kedatangan responden di IGD adalah $7,89 \pm 6,44$ jam dengan interval tercepat adalah 1 jam dan interval paling lama adalah 28 jam 30 menit. Rata-rata interval waktu kedatangan dalam penelitian ini lebih lama dibandingkan penelitian lain yang hanya 4.51 jam dan 4.8 jam. $^{20,21}$ Angka ini jauh melampaui golden periode penanganan pasien dengan Sindrome Koroner Akut (SKA), baik STEMI maupun NSTEMI. American Hearth Association (AHA) menetapkan bahwa cut of point penanganan Sindrome Koroner Akut (SKA) sebagai kasus kegawatdaruratan kardiovaskular adalah $\leq 2$ jam post angina.

Pada penelitian ini, interval kedatangan dikelompokkan menjadi dua kategori berdasarkan nilai cut-off point dari penelitian sebelumnya, yaitu terlambat $(>2$ jam) dan tidak terlambat ( $\leq 2$ jam). ${ }^{8}$ Jumlah responden yang terlambat adalah 34 orang (68\%) dan jumlah responden yang tidak terlambat adalah 16 orang (32\%). Pasien yang datang terlambat ( $>2$ jam setelah onset muncul) di IGD mempunyai risiko kematian 3 kali lebih tinggi dibandingkan dengan pasien yang datang lebih awal ( $\leq 2$ jam setelah onset muncul) dengan nilai odd ratio (OR) 3,2. ${ }^{8}$

Pada penelitian ini, interval kedatangan berpengaruh secara bermakna terhadap tekanan darah sistolik. Hal ini berarti bahwa semakin terlambat datang di IGD maka semakin menurun tekanan darah sistolik pasien ( $p$-value $=0.015$ ). Penurunan tekanan darah sistolik mencerminkan penurunan curah jantung. ${ }^{8}$ Penurunan curah jantung menyebabkan gangguan hemodinamik, memicu terjadi gangguan oksigenasi dan perfusi ke jaringan dan menyebabkan syok. Syok merupakan gangguan sirkulasi yang diartikan sebagai kondisi ketidakadekuatan transport oksigen ke jaringan (hipoksia), yang dalam proses lanjut dapat menyebabkan mortalitas jaringan bahkan dapat mengancam kehidupan. ${ }^{22}$

Adapun 2 faktor yang terbukti secara signifikan sebagai penyebab pasien terlambat datang di IGD, yaitu selfmedication dan pola pencarian pengobatan.

\section{a. Self-medication}

Tabel 3. Hasil Analisis Self-Medication sebagai Penyebab Pasien Terlambat Datangdi IGD $(n=50)$

\begin{tabular}{|c|c|c|c|c|}
\hline \multirow{3}{*}{$\begin{array}{c}\text { Penyebab } \\
\text { Keterlambatan }\end{array}$} & \multicolumn{2}{|c|}{ Interval Kedatangan } & \multirow{3}{*}{ Total } & \multirow{3}{*}{$\mathbf{P}$} \\
\hline & $\begin{array}{c}\text { Tidak } \\
\text { Terlambat }\end{array}$ & Terlambat & & \\
\hline & $\mathbf{N}$ & $\mathbf{N}$ & & \\
\hline $\begin{array}{l}\text { - } \text { Melakukan } \\
\text { self- } \\
\text { medication }\end{array}$ & 2 & 34 & 36 & \\
\hline $\begin{array}{l}\text { - } \text { Tidak } \\
\text { melakukan } \\
\text { self- } \\
\text { medication }\end{array}$ & 14 & 0 & 14 & $0.000^{*}$ \\
\hline Total & 16 & 34 & 50 & \\
\hline
\end{tabular}

Sumber : Data Primer, 2016

Analisis Faktor Yang Mempengaruhi “Prehospital Delay Time” Pada Pasien Non-St Elevation Myocardial Infarction (Nstemi) 
Bahwa hasil analisis menggunakan uji Chi-Square menunjukkan upaya selfmedication yang dilakukan oleh responden terbukti secara signifikan berperan sebagai penyebab pasien terlambat datang di IGD ( $p$ value $=0,000$ ). Adapun self-medication yang dilakukan oleh responden ketika keluhan nyeri dada muncul antara lain minum obat warung, kerokan, istirahat, memakai balsem, minum minuman hangat, menyeka badan dengan air hangat, dan diuap/diasap.

Hasil penelitian ini didukung bahwa upaya self-medication yang dilakukan pasien setelah serangan angina merupakan penyebab pasien datang terlambat di IGD. ${ }^{13}$ Dengan demikian, perlu adanya kampanye kepada masyarakat dengan sasaran utama adalah masyarakat yang seringkali melakukan upaya self-medication. Kampanye kesehatan tersebut meliputi pendidikan tentang faktor risiko, upaya pencegahan, tanda dan gejala serta komplikasi NSTEMI, serta tindakan segera yang harus dilakukan. Kampanye kesehatan ini bertujuan untuk meningkatkan kesadaran publik, harapannya dengan adanya kesadaran publik yang baik dari masyarakat akan membantu memperpendek interval kedatangan pasien.

\section{b. Pola pencarian pengobatan}

Tabel 4 menunjukkan bahwa hasil analisis menggunakan uji Chi-Square menunjukkan pola pencarian pengobatan yang dilakukan responden terbukti secara signifikan berperan sebagai penyebab pasien

terlambat datang di IGD ( $p$-value=0,002).

\begin{tabular}{|c|c|c|c|c|}
\hline Pola & Interval K & atangan & & \\
\hline $\begin{array}{l}\text { Pencarian } \\
\text { Pengobatan }\end{array}$ & $\begin{array}{c}\text { Tidak } \\
\text { terlambat }\end{array}$ & $\begin{array}{c}\text { Terlamb } \\
\text { at }\end{array}$ & Total & $\mathbf{P}$ \\
\hline $\begin{array}{ll}\text { - } & \text { Ke IGD RS } \\
& \text { Pusat } \\
& \text { Rujukan }\end{array}$ & 14 & 14 & 28 & \\
\hline $\begin{array}{l}\text { - Ke YanKes } \\
\text { lain/Dukun }\end{array}$ & 2 & 20 & 22 & $0,002^{*}$ \\
\hline Total & 16 & 34 & 50 & \\
\hline
\end{tabular}

Sumber: Data Primer, 2016

Dalam penelitian ini, pola pencarian pengobatan responden sebelum ke IGD Rumah Sakit Pusat Rujukan antara lain menuju ke praktek dokter/perawat/bidan $(48,48 \%)$, puskesmas $(18,18 \%)$, rumah sakit daerah $(27,27 \%)$ dan bahkan dukun/kyai $(6,07 \%)$.

Gambar 1 Rata-rata Waktu Kedatangan Responden (dalam jam) di IGD berdasarkan J enis Layanan Kesehatan

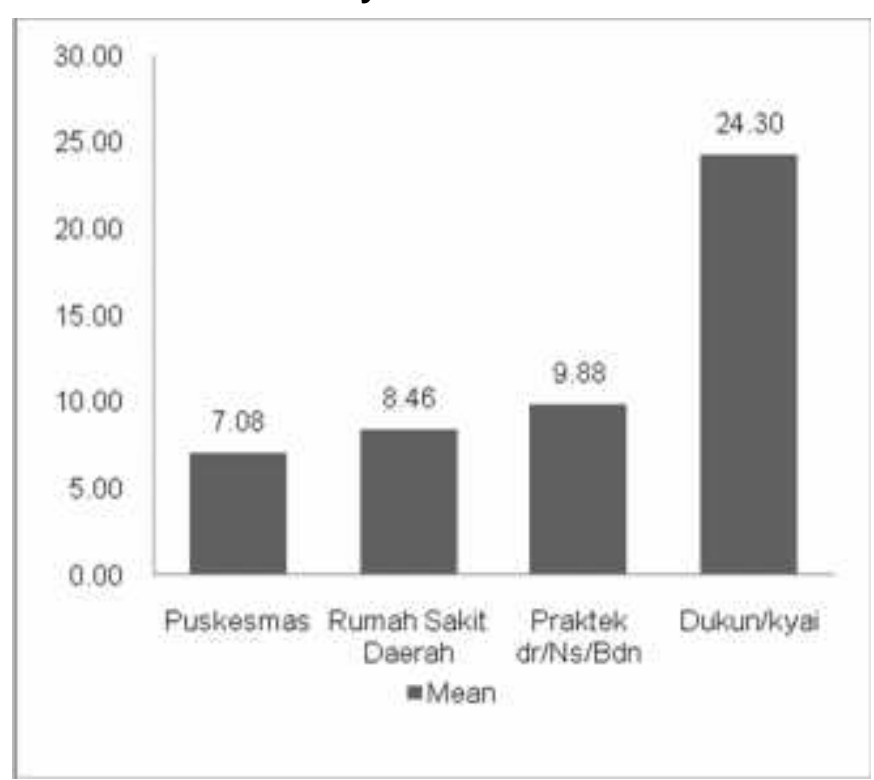

Hasil penelitian ini didukung bahwa pola pencarian pengobatan merupakan penyebab pasien datang terlambat di IGD dengan pola 
pencarian pengobatan antara lain menuju ke layanan puskesmas, praktek dokter atau tenaga kesehatan lain, klinik atau rumah sakit daerah. ${ }^{15}$ Berdasarkan hasil analisis menggunakan uji one-way ANOVA, menunjukkan bahwa responden yang mempunyai pola pencarian pengobatan ke dukun/kyai paling terlambat datang di IGD dibandingkan responden yang mempunyai pola pencarian pengobatan ke puskesmas, praktek dokter/perawat/bidan maupun ke rumah sakit daerah.

Responden yang mencari pengobatan ke dukun/kyai berpersepsi bahwa keluhan yang dirasakan adalah pengaruh kekuatan makhluk gaib. Responden beranggapan bahwa mereka tidak mempunyai riwayat penyakit jantung sebelumnya dan tidak ada keluhan nyeri dada, mereka juga sudah melakukan upaya self-medication sehingga percaya keluhan akan hilang dengan sendirinya dengan upaya tersebut, padahal tanda dan gejala NSTEMI tidak hanya nyeri dada namun juga nyeri epigastrik, keringat dingin, mual, muntah, lemes, sesak nafas maupun pusing, bahkan beberapa pasien NSTEMI tidak melaporkan adanya keluhan nyeri dada. ${ }^{23}$

Pada penelitian ini, 28 responden (56\%) merupakan pasien rujukan dari layanan PHC (Primary Health Care). Di Indonesia, sistem rujukan di layanan PHC belum tertata dengan baik khususnya pada kasus kegawatdaruratan kardiovaskular. Pasien dengan kasus kegawatdaruratan dari praktek dokter/perawat/bidan seringkali dirujuk terlebih dahulu ke puskesmas dan dari puskesmas dirujuk lagi ke rumah sakit daerah, padahal di rumah sakit daerah seringkali belum terdapat dokter spesialis dan fasilitas pelayanan kesehatan yang memadai untuk menangani kasus kegawatdaruratan kardiovaskular. ${ }^{24} \mathrm{Hal}$ yang sama terjadi juga pada penelitian ini, seringkali pasien dengan kasus kegawatdaruratan kardiovaskular yang berasal dari layanan PHC seperti puskesmas atau praktek dokter/perawat/bidan tidak langsung segera dirujuk ke IGD Rumah Sakit Pusat Rujukan namun dirujuk dahulu ke rumah sakit daerah. Kondisi inilah yang menyebabkan diagnosis awal dan terapi definitif awal tidak dapat segera dilakukan. ${ }^{25}$ Kapabilitas tenaga kesehatan, baik perawat maupun dokter dan fasilitas di layanan PHC berpengaruh terhadap sistem rujukan pasien. Layanan PHC yang tidak mempunyai standar operasional prosedur tentang sistem rujukan pada pasien dengan kegawatdaruratan kardiokaskular, tingkat pengetahuan dokter umum di layanan PHC yang masih rendah tentang kegawatdaruratan kardiovaskular dan fasilitas layanan PHC seperti ambulans yang belum tersedia mengakibatkan sistem rujukan di layanan PHC menjadi belum terorganisir dengan baik. ${ }^{25}$

\section{KESIMPULAN}

Rata-rata interval kedatangan responden di IGD rumah sakit pusat rujukan di Provinsi 
Jawa Timur adalah 7,89 $\pm 6,44$ jam, angka ini jauh melampaui golden periode penanganan pasien dengan Sindrome Koroner Akut (SKA), baik STEMI maupun NSTEMI. American Hearth Association (AHA) menetapkan cut of point penanganan Sindrome Koroner Akut (SKA) sebagai kasus kegawatdaruratan kardiovaskular adalah $\leq 2$ jam post angina.

Faktor - faktor yang berperan sebagai penyebab pasien terlambat datang di IGD, yaitu self-medication dan pola pencarian pengobatan. Self-medication yang dilakukan antara lain minum obat warung, kerokan, istirahat, memakai balsem, minum minuman hangat, menyeka badan dengan air hangat, dan diuap/diasap. Pola pencarian pengobatan responden sebelum ke IGD rumah sakit pusat rujukan antara lain menuju ke praktek dokter/perawat/bidan, puskesmas, rumah sakit daerah dan bahkan dukun/kyai. Responden yang mencari pengobatan ke dukun/kyai berpersepsi bahwa keluhan yang dirasakan adalah pengaruh kekuatan makhluk gaib. Responden beranggapan bahwa mereka tidak mempunyai riwayat penyakit jantung sebelumnya dan tidak ada keluhan nyeri dada, padahal tanda dan gejala NSTEMI tidak hanya nyeri dada namun juga nyeri epigastrik, keringat dingin, mual, muntah, lemes, sesak nafas maupun pusing, bahkan beberapa pasien NSTEMI tidak melaporkan adanya keluhan nyeri dada. Mereka juga sudah melakukan upaya selfmedicationsehingga percaya keluhan akan hilang dengan sendirinya dengan upaya tersebut.

Berdasarkan hasil penelitian ini, disarankan perlu adanya kampanye kesehatan dari petugas kesehatan yang bertujuan untuk meningkatkan kesadaran sejak dini masyarakat tentang kasus kegawatan kardiovaskular, meliputi faktor resiko, upaya pencegahan, tanda dan gejala serta komplikasi, serta tindakan segera yang harus dilakukan post serangan nyeri dada dengan tujuan untuk meningkatkan kesadaran publik. Dengan adanya kesadaran publik yang baik dari masyarakat akan membantu memperpendek interval keterlambatan. Selain itu, sistem rujukan layanan primer $(\mathrm{PHC})$ perlu ditata kembali dengan baik khususnya pada kasus kegawatdaruratan kardiovaskular.

\section{TERIMA KASIH}

1. Direktur AKPER Notokusumo Yogyakarta

2. Ketua LPPM AKPER Notokusumo Yogyakarta

\section{KEPUSTAKAAN}

1. Anderson, JL and Doty, JR. Bypass surgery after non-st-segment elevation myocardial infarction. Better early than late?.J ournal of The American Heart Association. 2010. Volume 3, (4), Hal. 428-430

2. Darling, C.E., Fisher, K.A., McManus, D.D., Coles, A.H., Spencer, F.A., Gore, J.M., Goldberg, R.J.,.Survival after hospital discharge for ST-segment elevation and non-ST-segment elevation acute myocardial infarction: a populationbased study. Clinical E pidemiology. 2013. Volumen 5, Hal. 229 - 236 
3. Nikus, KC., Eskola, MJ., Virtanen, VK., Harju, J., Huhtala, H., Mikkelsson, J., Karhunen, PJ., Niemela. Mortality of patients with acute coronary syndromes still remains high: A follow-up study of 1188 consecutive patients admitted to a university hospital. Annals of Medicine. 2007. Volume 39, Hal. 63-71

4. Kementerian Kesehatan RI. Penyakit Tidak Menular. Buletin Jendela Data dan Informasi Kesehatan. Semester II. Jakarta : Pusat Data dan Informasi Kementerian Kesehatan RI. 2012

5. Gartner, C., Walz, L., Bauernschmitt, E., Ladwig, KH.The Causes of Prehospital Delay in Myocardial Infarction. Dtsch Arztebl Int. 2008. Volume 105, (15), Hal. 286-291

6. Hitchcock, T., Rossouw, F., McCoubrie, D., Meek, S. Prehospital Care. Observational study of prehospital delays in patients with chest pain. Emergency Medical J ournal. 2003. Volume 20, Hal. 270-273

7. Goldberg, RJ., Granger, CB., Avezum, A., Brieger, D., Budaj, A., Goodman, SG.Extent of, and factors associated with, delay to hospital presentation in patients with acute coronary disease (the GRACE registry). American J ournal Cardiol. 2002. Volume 89, Hal. 791-796

8. Pitsavos, C., Kourlaba, G., Panagiotakos, D.B., Stefanadis, C. Factors associated with delay in seeking health care for hospitalized patients with Acute Coronary Syndromes: The GREECS Study. Hellenic J ournal Cardiol. 2006. Volumen 47, Hal. 329-336

9. Johansson, I., Stromberg, A., Swahn, E., Sweden, L. Factors related to delay times in patients with suspected acute myocardial infarction. Heart \& Lung. 2004. Volumen 33, (5), Hal. 291-300

10. Henriksson, C. Digital Comprehensive Summaries of Uppsala Disertations from the Faculty of medicine 685. Coronary Heart Disease and Early Decision Making, from Symptoms to Seeking Care. Studies with Focus on Pre-hospital Delay in Acute Myocardial Infarction Patients. ACTA. Universitatis Upsaliensis Uppsala. 2011
11. Perez, GE., Costabel, JP., Gonzalez, N., Zaidel, E., Altamirano, M., Schiavone, M., Carrizo, A., Iglesias, RM. Acute Myocardial Infarction in Argentina. CONAREC XVII Register. Argentine J ournal of Cardiology. 2013. Volumen 81, Hal. 365-373

12. Riegel, B., Moser, DK., Anker, SD., Appel, LJ., Dunbar, SB., Grady, KL., Havranek, EP., Gurvutz, MZ., Lee, CS., Lindenfeld, J., Peterson, PN., Pressler, SJ., Schocken, DD., Whellan, DJ. State of the science: promoting self-care in persons with Heart Failure: A scientific statement from the American Heart Association. 2009. American Journal Cardiol . 2009. Volume 120, Hal. 11411163

13. Farshidi, H., Rahimi, S., Abdi, A., Salehi, S., Madani, A. Factors associated with pre-hospital delay in patients with Acute Myocardial Infarction. Iranian Red Crescent Medical J ournal. 2013. Volume 15, (4), Hal. 321-316

14. Sugiarto, DCE. Hubungan faktor prehospital dengan interval keterlambatan pada pasien nyeri dada kardiak iskemik yang datang ke Rumah Sakit Umum dr. Saiful Anwar Malang. Fakultas Kedokteran. Universitas Brawijaya. Malang. 2012

15. Sjostrom-Strand, A., Fridlund, B. Women's descriptions of symptoms and delay reasons in seeking medical care at the time of a first myocardial infarction: A qualitative study. International J ournal of Nursing Studies. 2008. 45, Hal. 10031010

16. Sastroasmoro, S dan Ismael, S. Dasardasar metodologi penelitian klinis. Jakarta: Sagung Seto. 2011

17. Budiarto, E. Metodologi penelitian kedokteran: sebuah pengantar. Jakarta: EGC. 2002

18. Aziz, A. Metode penelitian keperawatan dan teknik analisis data. Jakarta: Salemba Medika. 2007

19. McKee, G., Mooney, M., O'Donnell, S., O'Brien, F., Biddle, M.J., Moser, D.K. Multivariate analysis of predictors of prehospital delay in acute coronary syndrome. Internasional J ournal of 
Cardiology. 2013. Volume 168, Hal. 27062713.

20. Terkelsen, C.J., Lassen, J.F., Norgaard, B.L., Gerdes, J.C., Jensen, T., Gotzsche, L.B., Nielsen T.T., Andersen, H.R. Mortality rates in patients with STelevation vs non-ST-elevation acute myocardial infarction: observations from an unselected cohort. European Heart J ournal. 2004. 26, Hal. 18-26

21. Fitria, C.N. Syok dan Penanganannya. Gaster. Dikutip dari: http://download.portalgaruda.org/article.p hp?article $=119499 \& v a l=5466$. 2010, Vol. $7,(2)$.

22. Overbaugh, KJ. Acute Coronary Syndrome: even nurses outside the ED should recognize its signs and symptoms. American Journal of Nursing. 2009. Volume 109(5), Hal, 45-52

23. Shrestha, J. Evaluation of access to primary healthcare a case study of Yogyakarta, Indonesia. International Institute For Geo-Information Science And Earth Observation. Enschede: The Netherlands. 2010

24. Williams, C. Trip report: Indonesia maternal referrals in the regionalization or perinatal care study Tanjungsari, Indonesia. The Agency for International Development. 2003

25. Faulkner, A., Mills, N., Bainton, D., Baxter, K., Kinnersley, P., Peters, TJ, Sharp, D. A systematic review of the effect of primary care-based service innovations on quality and patterns of referral to specialist secondary care. British J ournal of General Practice. 2003. Volume 53, Hal, 878-884

26. Sastroasmoro, S dan Ismael, S. DasarDasar Metodologi Penelitian Klinis. Jakarta: Sagung Seto. 2011 